\title{
CONTRIBUIÇÕES DA RÍTMICA DE DALCROZE À \\ PREPARAÇÃOO DO COLABORADOR MUSICAL
}

\section{DALCROZE EURHYTHMICS AND THE EDUCATION OF COLLABORATIVE MUSICIANS}

\author{
Daniela Amaral Rodrigues Nicoletti \\ Universidade de São Paulo \\ danielaamaral@usp.br
}

Silvia Berg

Universidade de São Paulo

silviaberg@usp.br

\section{Resumo}

presente artigo, pautado na pesquisa da obra de Émile JaquesDalcroze, trata das contribuições que sua Rítmica pode vir a oferecer à preparação do pianista, com foco na colaboração musical, à medida que tem por objetivos a superação de arritmias, automatismos e a integração entre o corpo e a audição, bem como o desenvolvimento da escuta e da criatividade. Para isso, são delineadas as particularidades dessa atuação artística, tomando como principal referência teórica a obra de Martin Katz. Entende-se que essas contribuições podem, do mesmo modo, ser aplicadas a outros instrumentistas que se dedicam à música de câmara, pelas suas semelhanças performáticas, no que diz respeito especialmente à necessidade de perceber e corresponder musicalmente ao outro em uma interpretação conjunta.

Palavras-chave: colaboração musical; pedagogia musical, rítmica dalcroze; performance musical; música de câmara. 


\section{Abstract}

Based on a research into Émile Jaques Dalcroze's work, this paper deals with the contributions that his Eurhythmics can offer to the collaborative pianist's education, once this method aims at developing skills for overcoming "arrhythmias" and automatisms and for promoting body and hearing integration. To this purpose, it is necessary to point out some particularities of the specialized field of musical collaboration and here Martin Katz's thought proves to be of great theoretical importance. These contributions can also apply to other instrumentalists dedicated to chamber music, given their similarities to the pianists in the fabric of a performance, especially in what concerns the need of fitting in with the partners and giving musical responses in ensemble playing.

Keywords: musical collaboration; musical pedagogy; dalcroze eurhythmics; musical performance; chamber music.

\section{Introdução}

$\bigcirc$ exercício da função de pianista colaborador requer o desenvolvimento de muitas aptidões e capacidades, o domínio de múltiplas competências interdisciplinares, além da técnica instrumental e de conhecimentos teóricos musicais. Se o estudo e a análise da partitura, o contexto histórico, estético e as características estilísticas da obra, bem como seu conteúdo poético-literário são para isso de cabal importância, não menos relevante é a capacidade de transitar com autonomia da notação para a execução musical, dispondo de acuidade perceptiva e capacidade de reação, além de traduzir e representar o que está além da escritura, sugerindo subtextos, dando ensejo ou salientando uma intenção composicional ou do intérprete.

A denominação colaborador substituiu, a partir do século XX, em especial nos Estados Unidos, como informa Ballestero (2014), outros termos, tais quais acompanhador, correpetidor e repassador, designando, de maneira mais adequada e abrangente, a função do pianista como intérprete, preparador, ensaiador, quando esta se associa à música vocal ou coral, instrumental ou orquestral. Desse modo, o pianista assume 
a função de colaborador, partícipe criativo da performance musical, agregando ideias e ampliando o sentido da obra, além de auxiliador na interpretação, à medida que proporciona estabilidade estrutural, quanto a aspectos como tempo/ andamento, realização rítmica e agógica, contexto harmônico, equilíbrio sonoro e fraseado ou condução melódico-temática. $\bigcirc$ pianista colaborador necessita, portanto, de grande acuidade perceptiva do outro, estabelecendo com ele um diálogo vivo e atual e correspondendo ao que a performance musical pode oferecer no momento da sua realização, incluindo variantes e matizes interpretativos, de ordem física ou de adequação acústica, afetiva ou emocional. Katz argumenta que:

Preocupa de início, no entanto, a noção de que colaboração é meramente sincronização rítmica, alinhamento vertical, juntamente com o cuidado de não se tocar forte demais. É certo que tanto o conjunto perfeito quanto o bom equilibrio sonoro com o parceiro são essenciais [...], mas eles são apenas uma pequena parte da grande figura da colaboração, e talvez a menos imaginativa de todo o nosso trabalho. [...] Alguns desses desafios demandam nosso entendimento físico de como o nosso parceiro se sente; outros são inteiramente subjetivos como contar histórias ou manipular emocionalmente nossos parceiros e nossa audiência. (KATZ, 2009, p. 3)'

Do mesmo modo, a pesquisa contemporânea da performance musical, de acordo com Lima (2006, p. 13), tem favorecido uma concepção mais ampla, desde o próprio sentido etimológico do termo, que integra a acepção de interpretação, execução e prática, para abarcar um espectro extenso de saberes e capacidades, incluindo conhecimento intuitivo, sensibilidade, emoção e cultura do executante. A ideia de performance musical sobrepuja, portanto, a preocupação

I Of immediate concern, however, is the notion that collaboration is merely rhythmic synchronization, vertical alignment, if you will, along with the care not to play too loudly. To be sure, both perfect ensemble and good balance with one's partners are essential [...] but they are only a small part of the big picture of collaboration, and perhaps the least imaginative of all our jobs. [... S Some of these challenges demand our physical understanding of how our partners feel; others are entirely subjective as we wordlessly tell stories or emotionaly manipulate our partners and our audience." (KATZ, 2009, p. 3) 
mecanicista da prática e a racionalidade da episteme analítica, "na sua tendência fortemente exclusivista, estruturalista e neopositivista", como adverte Duprat (apud LIMA, 2006, p. 17), abrindo, assim, aos executantes, uma gama de possibilidades de escolha, que "processam-se em qualquer nivel de consciência, até mesmo nas escolhas inconscientes que ele assumiu em razão das inúmeras variáveis que coabitam o universo interpretativo".

Viés teórico e tecnicista da formação pedagógica do músico profissional, em detrimento da própria acuidade auditiva, despertou a preocupação do compositor e pedagogo suiço Émile Jaques-Dalcroze (1865-1950) desde a sua primeira experiência pedagógica, como professor de harmonia no Conservatório de Genebra, entre 1892 e 1910. A dificuldade de seus alunos de ouvir ou conceber mentalmente as harmonias que escreviam e realizar vocalmente as músicas impulsionou suas pesquisas sobre o aprendizado de música. A princípio, dedicouse à educação auditiva dos seus alunos, no entanto, não tardou a concluir que também "a musicalidade unicamente auditiva revelava-se como uma musicalidade incompleta", usualmente ocultando deficiências que designou "arritmias musicais" (DALCROZE, 1920, p. 5).

\section{A integração entre corpo e audição}

Jaques-Dalcroze observou experimentalmente que a apreensão dos elementos de natureza motriz e dinâmica da música não dependia apenas do ouvido, mas da relação entre sistema muscular e nervoso, do organismo inteiro ("de l'organisme tout entier"), da "harmonização entre o espírito e o corpo". Isso instigou a expansão da sua experiência

Em busca das relações entre a mobilidade e o instinto auditivo, entre a harmonia dos sons e a das durações, entre o tempo e a energia, entre o dinamismo e o espaço, entre a música e o caráter, entre a música e o temperamento, entre a arte musical e a da dança. (DALCROZE, 1920, p. 6)

autor reparou que as dificuldades rítmicas não se restringiam ao controle dos pequenos músculos isolados dos dedos, mãos ou braços, solicitados para a execução musical ao piano; ao contrário 
disso, acometiam, em geral, o sistema muscular, como um todo, que apresentava, nesses casos, alguma espécie de resistência ou rigidez, manifesta em ações como andar ou equilibrar-se em uma parada súbita, dificuldade em dissociar atos ou dosar energia, conforme a necessidade do movimento. Atribuiu os entraves a ritmos corporais, que se suporiam espontâneos, a hábitos sociais da modernidade urbana, relacionados à mecanização instrumental das mais diversas ações cotidianas e da locomoção, que historicamente reduziam a amplitude das experiências motoras, sensíveis - especialmente auditivas e táteis - e espaciais.

Os ritmos naturais, ou seja, aqueles que seriam ingênitos ao ser humano e não dependeriam de treinamento, resultariam de uma colaboração equilibrada entre os sistemas muscular e nervoso. Uma perturbação nesse âmbito, desencadearia "uma desordem em todo o organismo, uma desarmonia entre todas as partes do indivíduo, que comprometeria a liberdade de funcionamento do conjunto das faculdades psicofísicas" (DALCROZE, 1948, p. 158). Por isso, conclui que "o tratamento da arritmia deve ser empreendido no organismo inteiro, antes de ser aplicado a uma parte dele" (ibidem, p. 173), ou seja, tratando-se a origem mais profunda e não a manifestação mais superficial.

Um outro aspecto salientado por Jaques-Dalcroze como propósito de sua Rítmica seria a superação ou ruptura de automatismos, de gestos inúteis, sem sentido, contraídos inconscientemente por repetição substituídos por novos automatismos, a partir da educação consciente do movimento - e, consequentemente, do seu desperdício de energia, bem como dos dispêndios nervosos desnecessários ou descomunais, "saltos de humor, brusquidões, irregularidades, impaciência, depressões e hipersensibilidades", pois "um ritmo natural convenientemente efetuado em tal estado de espírito perde sua regularidade e sua facilidade se este estado de espírito se encontra alterado (DALCROZE, 1948, p. 157)." “Economizar, equilibrar, essa deve ser nossa divisa (ibidem, p. 166)."

Por isso também, Jacques-Dalcroze recomenda que não haja predominância do aspecto cerebral sobre o aspecto físico (ibidem, p. 162), que a complexidade dos exercícios não chegue a provocar fadiga cerebral nos educandos, já que "para fazer o corpo participar da ação cerebral, é importante que essa não absorva todas as 
forças do ser" (ibidem, p. 164). Referindo-se em especial às crianças, o educador deveria, de acordo com isso, lançar mão de jogos, ao menos a metade da aula e fazer com que a introdução de ritmos novos e esquecidos aconteça em meio a outros naturais ou orgânicos. Além disso, ele deve observar sempre o estado dos educandos e, ao menor sinal de fadiga, como momentos de falta de atenção e bocejos, propiciar-lhes o repouso, seja através de exercícios de relaxamento, seja por apelos diretos à sua curiosidade e imaginação. É pela intervenção frequente do "estado completo de descontração", que se pode indicar aos educandos "as relações estreitas entre as nuances dinâmicas musculares e os diversos graus da duração, como os diversos graus do espaço" (DALCROZE, 1948, p. 163).

Dalcroze aponta a necessidade da aquisição da técnica da parada, do repouso e do silêncio. Os propósitos da Rítmica, conforme - autor são: desobstruir (déclancher) os ritmos corporais espontâneos (com os "hops" ou comandos inopinados); equilibrar os centros nervosos e os dinamismos musculares, apelando sempre à concentração de espírito, diminuindo os ritmos intempestivos e reforçando os ritmos úteis; dar livre curso à imaginação e ao sentimento, ao harmonizar as funções corporais e espirituais. Para isso, os exercícios da aula de Rítmica são acompanhados de comandos que têm, nas palavras do próprio autor, a função de provocar ora movimentos ou interrupções súbitas, ora combinações de parada e atividade; pôr o espírito em condições de escolher, dentre o conjunto dos músculos, aquele que for mais necessário à ação requisitada e imobilizar os outros; aliviar o sistema nervoso, de modo que os comandos do espírito sejam imediata e integralmente executados; associar ou dissociar os ritmos impostos; combinar e intercambiar os ritmos espontâneos com os controlados pela razão; influenciar o espírito com o impulso irresistivel da rítmica instintiva, assim como influenciar o corpo com a energia dos centros de volição - em suma, "penetrar as forças dos subconsciente pelo afluxo do consciente e vice-versa (ibidem, p. 159)".

Os comandos gestuais, verbais ou sonoros agem sobre a vontade e os reflexos, segundo Jaques-Dalcroze, educando apenas o consciente ou o inconsciente dos educandos, enquanto a música, "substrato de todas as emoções humanas através dos tempos" (ibidem, p.161), age sobre a sensibilidade nervosa e o sentimento. Por isso, ele 
sublinha a importância de o ensino da Rítmica contemplar também melodia, harmonia, dinâmica e durações musicais, estimulando sempre as faculdades de imaginação ou invenção.

\section{Primazia à escuta e às relações entre cérebro, ouvido e laringe}

Em sua experiência pedagógica nas classes avançadas do Conservatório de Genebra, Dalcroze percebeu logo que: "entre os estudantes mais velhos, as sensações acústicas eram retardadas por raciocínios antecipados e inúteis, enquanto que entre as crianças, elas se revelavam de um modo bem espontâneo e engendravam muito naturalmente a análise (DALCROZE, 1920, p. 5)". Assim, ele observou que as dificuldades de solfejo e harmonia deviam-se a insuficiências da capacidade auditiva dos alunos, e dedicou-se, a partir de então, ao desenvolvimento e ao aperfeiçoamento da escuta na sua classe, estimulando a percepção de gradações e nuances de altura, intensidade, sutilezas tímbricas, de suas combinações, temporais, agógicas, discernimento de notas na harmonia, de vozes na polifonia, nos seus desenhos contrapontísticos. À época, desenvolver a audição dos alunos no Conservatório era praticamente um contrassenso, pelo pressuposto de que os alunos de Música deveriam ser dotados de uma escuta pronta, dedicando-se quase que exclusivamente à destreza na execução instrumental. Mais que isso, exigia-se dos alunos compor sem lançar mão do piano, em nome do "talento", como dom inato e diferencial do Músico - ignorando-se que os resultados, na realidade, eram praticamente fortuitos e muitas vezes desastrosos.

No entanto, o autor notou, nesse mesmo período, que alguns estudantes, embora apresentassem um desenvolvimento normal de suas aptidões auditivas, enfrentavam dificuldades em emitir os sons, o que atribuiu à sua incapacidade no momento de "medir igualmente os sons e de ritmar suas sucessões de duração desigual”, ou seja, pela dificuldade em sentir a pulsação da música (beat) e a distribuição rítmica dentro dessas durações regulares. Percebeu nisso uma discrepância entre a inteligência musical e a capacidade corporal de realização do aparelho vocal. Dalcroze assinala a sequência das observações que deram origem à sua Rítmica, sempre a fim de solucionar as dificuldades práticas, experimentais, dos alunos: 
Eu concluí, a partir disso, que tudo que, em música, é de natureza motriz e dinâmica depende não apenas da audição, mas também de um outro sentido que eu pensava primeiramente ser o sentido tátil, já que os exercícios métricos efetuados pelos dedos favorecem o progresso dos alunos. No entanto, as reações que eu notava nas outras partes do corpo, além das mãos, enquanto se tocava piano: batidas dos pés, oscilações do tronco e da cabeça, estremecimentos por todo o ser, me incitaram logo a pensar que as sensações musicais, de natureza rítmica, revelam o jogo muscular e nervoso do organismo todo inteiro. Eu apliquei aos alunos exercícios de andar [marche] e parar e os habituava a reagir corporalmente à audição de ritmos musicais. (DALCROZE, 1920, p. 6, grifo nosso)

mestre inventa, então, exercícios a fim de estabelecer relações entre as sensações de percepção do som e as sensações vocais e assim "criar entre o cérebro, o ouvido e a laringe as correntes necessárias para fazer do organismo todo o que se poderia chamar uma orelha interior" (DALCROZE, 1920, p. 10). Buscava com isso propiciar sinergias entre os movimentos vocais e os gestos do corpo inteiro, entre a respiração e o ritmo, muito claro no caso do canto, na escansão das frases, mas de modo análogo em toda música.

Para tanto, era preciso dar primazia à escuta, deter a reação imediata de executar e anotar graficamente; ensinar a despertar o pensamento antes de traduzi-lo nas suas palavras. Dalcroze entende que o ritmo havia se tornado algo puramente intelectual no aprendizado musical. Era necessário, então, trazê-lo novamente para o corpo, incorporá-lo por meio de uma memória especial:

A imagem dessas experiências rítmicas corporais, gravadas e incessantemente renovadas no cérebro, desperta e desenvolve o senso rítmico; da mesma forma, mais tarde, a imagem das experiências acústicas do ouvido, igualmente gravada e sempre renovada no cérebro, despertará e desenvolverá o senso da tonalidade. (DALCROZE, 1920, p. 110) 
Além de preconizar um ensino experiencial com a Música anterior ao aprendizado de um instrumento, uma musicalização, em que se pudesse ouvir, sentir as vibrações dos sons no corpo, mover-se com a música, brincar com a ampla gama de emoções e sentimentos que ela desperta, improvisar, criar livremente - sem a preocupação de realizá-la no instrumento -, fruir uma música em diversos níveis de complexidade, mesmo muito antes de ser capaz de executar um dedilhado complexo, pois a escuta não ficaria estagnada, aguardando o treinamento técnico-corporal para isso.

Por fim, ele salienta a estreita relação e a mútua interferência entre aparelho fonador e sistema auditivo, o que faz com que seja distintamente importante o uso da voz no aprendizado musical:

A produção mecânica de sons em um instrumento não necessita de nenhum esforço do ouvido; este não serve senão como meio de controle $e$, mesmo sem ele, o controle da vista e do toque é suficiente para obter convenientemente uma afinação aproximativa. Ao contrário disso, os esforços empreendidos pelo aluno para assegurar a afinação dos sons vocais leva a um desenvolvimento progressivo das faculdades auditivas. Em outros termos, o ensino com o auxilio de um instrumento pode levar a ouvir [entendre] melhor, o que é baseado no canto leva a escutar [écouter] melhor. (DALCROZE, 1920, p. 26)

Além de distinguir assim níveis de escuta, apontando um trajeto de desenvolvimento da faculdade auditiva, Dalcroze reconhece a associação entre a escuta e o aparelho fonador, sendo esse responsável tanto pela recepção como pela emissão de sons, em uma relação de comprometimento mútuo, em que ouvir educa a voz e cantar aprimora a audição.

2 Essa diferenciação dos termos ouïr, écouter e entendre, ao que Pierre Schaeffer ainda acrescenta uma quarta escuta, comprendre, é sutil e controversa, adquirindo e transformando conotações historicamente. A mesma ambiguidade pode ser atribuida aos termos em português ouvir e escutar, como assinala Maria Trench Fonterrada (FONTERRADA, 2003, p. 128), ao se referir à distinção semelhante apontada por Willems. Porém, pode-se entender, neste caso, que Dalcroze faz alusão a uma complexidade e uma sutileza mais refinada, a partir de um ajuste mais minucioso do instrumento corporal pela via sensorial, enquanto receptor e emissor dos sons. 


\section{A improvisação e o desenvolvimento da intuição musical para Dalcroze}

Um dos elementos diferenciais da Rítmica como pedagogia musical é a improvisação. $O$ despertar da sensibilidade e o desenvolvimento da apreciação estética por meio de uma escuta com o ser inteiro estão sempre aliados à criação momentânea, sem a mediação do pensar, como manifestação de um veio subterrâneo, onde habita o que há de mais autêntico em cada um. Dalcroze insiste muitas vezes na importância de se conciliar o consciente e o inconsciente humano e, inclusive, abrir passagem ao subconsciente, camada em que se depositam profundamente as experiências formativas mais relevantes.

Para ele, o pensar muitas vezes obstrui o agir. $\bigcirc$ pedagogo entreviu na sua Rítmica a possibilidade de conciliar a inteligência e a vontade, por meio do sentir, capaz de graduar, regular e equilibrar a relação entre essas duas outras forças. Buscando referenciar sua crítica ao ensino tradicional em filósofos, nomeadamente, Montaigne, Helvetius, Locke, Leibnitz, Rousseau, Coethe e Schiller, o autor de Notes Bariolées remete-se a uma concepção pedagógica em que a Música e as artes justificam-se em um papel essencial: "a música era a conciliadora entre a inspiração e a medida, a arte de se exprimir em um ritmo pessoal" (DALCROZE, 1920, p. 107).

A intuição, frequentemente reprimida numa sociedade baseada no pensamento lógico-abstrato, sob esse ponto de vista, é portadora da singularidade de cada indivíduo. $\bigcirc$ compositor suiço valoriza o modo intuitivo de compor em oposição ao engenho de um pensamento meticuloso, surpreendendo-se com o que poderia ser a comprovação de sua tese: "Algumas obras que foram compostas febrilmente de um só jorro e sem preparação podem assim mesmo produzir uma impressão de ordem, de calma e de sagacidade que não se encontra sempre em composições longa e sabiamente meditadas" (DALCROZE, 1948, p. 109).

Para Dalcroze, a moderação dos antagonismos entre o querer, como impulso ou instinto corporal - ou como a pulsação, princípio vital perene, subjacente a qualquer ação humana - e, de outro lado, o sistema nervoso, com a sua exigência de controle, permitiria que a intuição assomasse de modo distintamente criativo, como as revelações feitas à consciência durante o estado de sono. A improvisação, com seu 
caráter imediato, enquanto ausência da tutela do intelecto, com suas premissas de regras, formas ou técnicas, seria, desse modo, capaz de propiciar essa atividade especialmente criativa, a expressão livre das particularidades de um sujeito. Assim, define a intuição:

A intuição é frequentemente o resultado de uma série de atividades interiores contínuas se exteriorizando bruscamente sob o choque inesperado de uma viva emoção. Durante o sono, o corpo repousa e o cérebro se libera de todos os entraves de natureza nervosa, sanguínea e muscular. A gente se revira na cama, a gente acorda e eis que a ideia se deflagra. (DALCROZE, 1948, p. 71)

sagaz observador, apesar de sua concepção clássica dos procedimentos composicionais, entende que o ritmo é imanente à vida e podem surgir de outras maneiras, independentemente da lógica:

Toda a composição musical é construída sobre ritmos diversos apresentados sob formas logicamente encadeadas, de modo a criar um ritmo geral equilibrando os diversos procedimentos de construção da obra. Os ritmos espontâneos entram intimamente em relação e suas particularidades se sucedem, opondo-se e combinando-se, formando um todo compacto onde circula uma intensa vida interior. (DALCROZE, 1948, p. 104)

E continua, encontrando o ritmo, inclusive nas artes visuais ou artes do espaço:

Na arquitetura, a construção se opera também sobre o ritmo das linhas regradas pela razão, aliando-se aí a medida à fantasia. A orquestração das sombras e das luzes corresponde em pintura à dos movimentos sonoros, dos timbres e dos dinamismos; é assim que em um quadro são orquestradas as formas, as tintas, as matérias picturais e a luminosidade. (DALCROZE, 1948, p. 104)

Da mesma forma, a vida e a criatividade, de acordo com a sua filosofia pedagógica, tem de permear todo o processo de ensino- 
aprendizagem: o ensino não pode ser "matéria requentada", na metáfora do autor. $\bigcirc$ mestre desaprova um ensino baseado na reprodução de fórmulas, procedimentos técnicos, juízos prontos, e acrescenta que cabe ao professor de música ir além disso na formação desse ouvinte-criador. Ainda sugere que se suscite a imaginação dos educandos, desde o princípio, na infância, referindo-se sempre à razão das propostas sem explicá-las, fecundando sua curiosidade, a partir dos detalhes da gestualidade da vida ordinária, inventando jogos e improvisando melodias (ibidem, p. 186).

A Música, para Dalcroze, deve ser veículo da expressão pessoal. Isso é afirmado reiteradamente até suas últimas anotações dispersas, dois anos antes do seu falecimento, à guisa de conclusão de uma vida inteira de reflexões sobre um sentido mais profundo de inserção da Música no itinerário humano:

Parece-me inútil ensinar uma técnica a alguém que não tem o desejo de se servir dela com um fim pessoal. É muito bonito saber exprimir as ideias dos outros, mas é preciso igualmente saber exprimir de tempos em tempos as suas próprias. (DALCROZE, 1948, p. 141)

Professor do Conservatório de Cenebra, ainda muito jovem, ele enuncia seu ideal, reportado por Berchtold:

$\bigcirc$ dia em que meus alunos estiverem desenvolvidos 0 suficiente para escutar como eu, dir-lhes-ei: "Não escutem mais com meus ouvidos, mas sirvam-se dos seus. Procurem combinações especiais, submetam-nas ao critério da sua própria experiência auditiva, sem se preocuparem com as regras que thes dei; expliquem-nos e me expliquem qual é o detalhe particular que thes faz considerar que soem bem as combinações de notas que o uso corrente reprova e uma vez que encontrem uma explicação, procurem combinações de formas diferentes onde aplicarão os mesmos princípios (DALCROZE apud BERCHTOLD, 2005, p. 46).

Mais do que tornar a escuta acurada, seu ideal formativo almeja a autonomia e a compreensão da música como construto históricocultural, aliando a sensibilidade à maturidade necessária à liberdade 
criativa. A prática da improvisação, a capacidade criativa, a seu ver, é imprescindivel não apenas aos alunos de composição, mas a todo aprendiz de Música, seja ele instrumentista, cantor - um músico profissional -, seja ele mais tarde apenas um ouvinte, consciente e criativo. $\bigcirc$ entendimento da técnica como ferramenta dota também - educando da confiança na sua capacidade de empregá-la em função da interpretação musical da notação, também entendida, por sua vez, como código, registro mnemônico e síntese, a que dará corpo e vida no instante.

\section{A crítica ao Conservatório, por Émile Jaques-Dalcroze}

pedagogo musical suiço viveu até seus 10 anos de idade na efervescente capital austríaca, Viena. Tendo uma longa filiação familiar à Música, sua formação dá-se nas artes, em especial na música, no teatro e na literatura, nos quais desenvolve seus pendores pessoais, desde muito cedo manifestos. $\bigcirc$ fato de ter cultivado essas artes de modo não excludente durante seu período de formação musical, escrevendo e participando de encenações teatrais, parece ter cunhado sua relação distinta com a música, bem como seu interesse em transformar os processos de ensino-aprendizagem musicais e expandir suas fronteiras.

Posteriormente, sua experiência como regente na Argélia, então colônia francesa, revela ao jovem músico um universo novo, em que a música incorporada da cultura autóctone mostrava uma diferente articulação com a vida, dotando os músicos da orquestra folclórica de um outro sentido, como um instinto rítmico. $\bigcirc$ modo diferente de sentir e dividir as durações temporais entre essas duas culturas criou a necessidade de uma comunicação gestual diferenciada com o grupo.

Na condição de docente, 30 anos mais tarde, de volta ao Conservatório Musical de Cenebra, esse novo papel é desempenhado com uma postura compreensiva, reflexiva e consciente da sua responsabilidade, o que, juntamente com a revisão da sua própria trajetória de estudante, impele-o a uma solução criativa: encontrar novas estratégias pedagógicas para suprir as necessidades dos educandos. $\bigcirc$ caráter experimental e dialógico das suas propostas e a acuidade de sua observação, reformulando seus exercícios, a partir das aulas, 
leva-o a novas abordagens e novos pontos de vista para atender às suas dificuldades, entendendo-as a princípio como auditivas.

Seu objetivo inicial é o treinamento técnico para o exercício de uma função específica em uma perspectiva profissional, o que the permite entrever progressivamente o quanto a música alicerça-se profundamente no desenvolvimento humano, apontando a importância da presença dessa arte na trajetória de todo indivíduo. Isso inspirou seu projeto de reforma do ensino escolar, com a inclusão curricular da Música, divulgado como artigo em 1905, em uma das publicações do seu periódico Le Rythme (Un essai de réforme de l'enseignement musical dans les écoles). Pode-se entender esse momento de sua carreira artística e pedagógica como um marco em que a Música lança-se, do universo estrito do Conservatório, em direção ao entendimento mais amplo e complexo das suas relações com a vida e com as outras artes que caracterizou essencialmente 0 pensamento e a atuação do criador da Rítmica.

Cabe salientar aqui alguns aspectos que definem a instituição musical denominada Conservatório, em que residem pontos fundamentais da problematização do ensino musical feita por Dalcroze. $\bigcirc$ primeiro deles, a distinção entre competências e saberes necessários ao intérprete-instrumentista e ao compositor. Os primórdios desse tipo de organização, os Ospedali, datam do século XVII, na Itália, quando ocorre também um grande desenvolvimento da música instrumental, com o gênero camerístico, o advento do baixo contínuo e o estilo concertato, que dão lugar aos solos, e com eles a elevação da complexidade da execução técnica da música instrumental, alçada a um status autônomo.

A música, de forma geral, torna-se progressivamente independente das instituições religiosas, a partir desse momento, e passa a integrar a vida cultural das cidades, especialmente cultivada pelo mecenato nas cortes. Vasconcelos, em seu estudo sobre os Conservatórios, analisa suas origens:

Sob o ponto de vista da formação, a necessidade da instituição de uma escola deste tipo assentouna ideia base de racionalizar a transmissão dos saberes musicais, contribuindo para a divisão do trabalho, que progressivamente foi criando 
um estatuto autônomo do intérprete em comparação com o compositor. É fundamentalmente a partir desta dinâmica que a socialização da profissão de músico-intérprete se concretizou. (VASCONCELOS, 2002, p. 36)

Disso decorrem dois efeitos, levados ao seu paroxismo no século XX: a separação entre execução instrumental e composição; e a racionalização dos saberes musicais, tornando mais do que pauta central, exclusiva, a técnica para o instrumentista e a teoria para o compositor. À medida que se aprofunda essa divisão do trabalho, perde-se alguns dos elementos essenciais a essa música instrumental, cuja falta Dalcroze assinala e busca recuperar por meio da sua Rítmica: a capacidade de improvisação, a sensibilidade estética e, propriamente, a escuta, desarmada do pensamento analítico e, em última instância, a própria arte, na sua dimensão criativa e de expressão pessoal. $\bigcirc$ modelo que se busca, então, é o do virtuose, e os estudos musicais restringem-se às partituras e à ferramenta básica da leitura e notação musical.

Dalcroze, no seu texto satírico em forma de diálogo, intitulado $\bigcirc$ piano e a menina do conservatório, toma por interlocutor um burguês caricato ou típico, o Senhor Qualquer, que se envaidece pelo sucesso de sua filha nos exames de piano, para denunciar a situação com que se depara em seu tempo. Assim ele sintetiza:

Antigamente os músicos artistas, sem exceção, conheciam todos os segredos técnicos da sua arte. Hoje esses segredos não são revelados senão aos futuros compositores. Enchemse os conservatórios de rapazes e moças que se gabam de bons dedos, bons pulmões, boas cordas vocais, e que, no entanto, não possuem nem bom ouvido, nem boa inteligência, nem uma bela alma. (DALCROZE, 1924, p. 166, grifos nosso)

Dalcroze avalia nisso uma decadência da arte, substituindo o artista pelo artífice, comparando o músico a um vidraceiro ou marceneiro, que também haviam perdido seu atributo artístico, só fazendo, então, imitar modelos ou realizar as concepções de desenhistas. Em seguida, assinala a raiz do problema: a pressuposição de que ouvido, inteligência e gosto musical sejam dons inatos do talento e não possam 
ser desenvolvidos. Ao contrário disso, afirma: "Poderá (um ensino bem compreendido) despertá-lo, formá-lo, se existir em gérmen." E completa, salientando o fim último do ensino musical na formação humana: "A não ser assim, tornar-se-ão papagaios e macacos, em vez de se tornarem músicos e homens" (DALCROZE, 1924, p. 168).

Esse pianista-improvisador, depois de expulso das aulas de Bruckner - que the recomendava esperar os 40 anos para começar a criar, só depois que os estudos de harmonia e contraponto constituíssem fundamentos muito sólidos para a composição - foi acolhido por Adolph Prosnitz e Hermann Graedener, no mesmo Conservatório Musical de Viena. $\bigcirc$ primeiro, segundo Dalcroze, bem ao contrário de Bruckner, costumava exigir que seus alunos se inspirassem com a emoção provocada pela interpretação de uma obra, para comentá-la livremente improvisando no sev estilo pessoal: "Assim se estabelecia uma espécie de colaboração entre o intérprete e o autor que animava a interpretação de uma arrepiante corrente de vida" (BERCHTOLD, 2005, p. 38). $\bigcirc$ segundo é lembrado por seu aluno pela boa recepção de um exercício de composição, em que havia cometido todos os erros permitidos (como dissonâncias com resolução muito retardada): ao invés de uma dura reprovação, "só faltou sufocar de tanto rir", pedindo antes que o jovem tocasse e ouvisse o efeito "pavoroso de se ouvir, embora engraçado" (lbid., p. 38).

Em sua própria jornada de aluno parece ter sido gestada a pedagogia que preconiza uma relação humana, de camaradagem, com os educandos, que thes permita experimentar a transgressão das normas tradicionais da música, segundo sua vontade criativa, dando vazão à sua personalidade e ao reconhecimento auditivo do que seja ou não interessante musicalmente e chegando, por fim, à compreensão da justificativa da interdição.

Dalcroze observa e aponta que a concentração exclusiva na racionalidade teórica e analítica, bem como na ação mecânica da realização instrumental - o que é assinalado também por Rudolf Steiner ( 1861 - 1925) como unilateralidades no desenvolvimento de capacidades e habilidades - é contrária e limitadora ao desabrochar da musicalidade, de que, por sinal, todo o ser humano é portador. Em $O$ piano e a menina do Conservatório (1905), ele salienta como faltas principais aos alunos desse ensino: o amor à música, a alegria e o prazer de fazer a música 
permear a vida e não ficar restrita aos exames. Do mesmo modo, refere-se ao o gosto musical, a que os dedos deveriam obedecer desde a primeira lição. "A base do ensino devia ser o estudo, não do meio mecânico de expressão, mas da ideia a exprimir" (DALCROZE, 1924, p.168). No texto, Dalcroze usa a comparação de um piano a um realejo para mostrar a inversão que a cultura mecanicista havia promovido.

Essa ginástica de dedos evidencia, para o criador da Rítmica, uma desconexão entre ouvido e músculos, entre pensamento e ouvido, e entre musculatura e memória - motivo pelo qual as músicas estudadas desse modo são esquecidas logo que deixam de ser repetidas. A falta de consciência sobre a própria ação corporal não deixa rastros, como os sulcos profundos da experiência estética proposta pela Rítmica, a fim de recuperar o sentido poético e a significação existencial da música. Dalcroze entrevê aí uma noção mais ampla da memória, mais profunda e mais complexa, superando novamente o dualismo mente e corpo, o que mais tarde será designado como memória corporal, inteligência corporal-cinestésica ${ }^{3}$ (CARDNER, 1994) ou mente incorporada4.

Mais que isso, Dalcroze percebe mesmo que o desenvolvimento muscular corresponde a um treinamento exaustivo ou uma hipertrofia de segmentos muito limitados em detrimento de outros, ou seja, nota a existência de um sistema muscular como uma cadeia global, cujo desequilibrio teria como efeito final a interferência prejudicial no que denominou sentido rítmico.

3 Gardner, buscando argumentos para a definição da inteligência corporal-cinestésica, faz uma interessante síntese a partir da análise do psicólogo britânico, Frederic Bartlett, sobre as características de uma performance corporal hábil. Sua análise aproxima um jogador de bola a um cirurgião pelo desempenho de sua atividade específica. Diz o autor: “(...) todos os desempenhos hábeis incluem uma noção bem aguçada de ritmo, onde cada trecho de uma sequência se encaixa no fluxo de uma maneira primorosamente colocada e elegante; pontos de repouso ou mudança, onde uma fase do comportamento está em uma extremidade, e alguma calibragem é necessária antes que a segunda entre em jogo; um senso de direção, uma meta clara para a qual a sequência esteve conduzindo, e um ponto de onde não há volta, onde um input adicional de sinais não produz mais resultados porque a fase final da sequência já foi ativada". (CARDNER, 1994, p. 162)

4 Wânia Storolli informa em sua tese que o conceito de mente incorporada foi apresentado pela primeira vez por Francisco Varela, Evan Thompson e Elanor Rosh (The embodied mind: cognitive science and human experience. Cambridge, Mass.: MIT Press, 1991). A partir de pesquisas de ciência cognitiva associadas à filosofia, os autores sustentam a interdependência entre conhecimento e experiência (STOROLLI, 2009, p. 50). 


\section{Dalcroze e a formação do pianista}

pedagogo suiço considerava que muitas dificuldades na execução e interpretação musical dos pianistas e instrumentistas, de maneira geral, eram decorrências de equivocos e insuficiências na formação convencional oferecida pelos Conservatórios para aos artistas, com seu foco na especialização, curto prazo e, sobretudo, sua ênfase ao virtuosismo e às regras tradicionais, em detrimento do desenvolvimento da criatividade e espontaneidade diante do instrumento - ou a ideia de que isso deveria ser posterior à conclusão de todo o estudo instrumental e teórico. Afirmava, pelo contrário, que "o estudo do virtuosismo não deve ser empreendido antes do desenvolvimento do espírito musical e o despertar das forças espontâneas do indivíduo" (DALCROZE, 1945, p. 180). Raramente, observou, os estudos puramente táteis eram precedidos de exercícios destinados a desenvolver, de modo geral, a musicalidade e a imaginação dos educandos e instigá-los a exprimir seus sentimentos ao piano, transformando-os em sensações, traduzindo-os e dando-lhes forma (DALCROZE, 1945, p. 177).

Para Dalcroze, ao músico adulto que almejava a criatividade e - cunho pessoal em suas interpretações, era necessária a superação de alguns entraves adquiridos ao longo dessa formação: seu cérebro deveria voltar a ser livre das regras arbitrárias, tolhedoras e dos exercícios convencionais sem relação com a musicalidade, que diminuem a sensibilidade original. Além disso, ele também deveria alcançar o estado de descontração física, que favorece a inventividade. Daí a importância de uma educação geral, que the permita realizar a síntese criativa dos seus movimentos físicos e psicológicos, orquestrando suas nuances:

Todo artista precisa, para ser completo, possuir uma técnica perfeita. Mas o estudo de procedimentos técnicos não é suficiente para formar um artista, e não deve, por consequência, alcançar isso até que uma educação geral dê ao aluno qualidades indispensáveis de impulsão, de sensibilidade, de leveza, de espírito, de ordem e de imaginação. (lbid., p. 123)

pianista Martim Katz, em seu livro The Complet Collaborator (2009), ao traçar os aspectos necessários à performance do pianista 
colaborador, refere-se à importância de se trazer para o corpo a ação do solista, em busca do seu objetivo último de alcançar a "completa fusão com o parceiro". Para isso, diz ele, o pianista colaborador deve respirar, pronunciar e flexionar as frases com o cantor ou, no caso da música instrumental, fazer o mesmo, imaginando sentenças ou palavras, como recurso para alinhar-se verticalmente com o solista e dar forma viva e orgânica à música. Katz acrescenta que todo músico beneficia-se cantando e, por exigência disso, respirando, "mas particularmente aqueles para quem o ar não é necessário para fazer seu instrumento funcionar." A respiração pode ser uma necessidade física ou expressiva, mas deve tornar-se natural, involuntária $e$ inconsciente para que o pensamento ou a informação demasiada não arruíne o processo espontâneo (KATZ, 2009, p. 20), o que pode ser entendido como o "desenvolvimento de um automatismo instintivo", definido por Dalcroze como produto de numerosas repetições de sentimentos e sensações (lbid., p. 191). Assim, ilustra o pianista, para terminar graciosamente uma frase, respirar e entrar novamente para frase seguinte, requer-se um tempo extra, imponderável ("a bit of extra, out-of-time"), o que só se torna possivel cantando e sentindo isso em seu próprio corpo. "Isso não é um julgamento intelectual, está enraizado na fisicalidade", completa Kałz (lbid., p.16).

Por outro lado, Katz salienta ser de suprema importância que o pianista não tenha nenhum impedimento físico, dedilhado complicado ou o mínimo de tensão com uma mudança de posição, que possa limitar sua flexibilidade e custar a sua liberdade para ser natural, como o seu parceiro (KATZ, 2009, p. 28) - ou, como diz Dalcroze sobre a liberdade em relação às regras e convenções pianísticas, "é necessário ao pianista tocar sem se preocupar com a maneira como toca" (DALCROZE, 1948, p. 191). Isso implica igualmente em uma autonomia do músico para realizar escolhas que resultem, por exemplo, na supressão de notas ou uma transgressão da tradição técnica, em prol da musicalidade.

Nos momentos em que o pianista assume a função de diretor, como designa Katz em um dos seus capítulos, expressando-se musicalmente, ou seja, quando realiza uma introdução, um interlúdio ou um pós-lúdio de um lied ou mélodie, faz-se essencial uma ativa e fecunda imaginação, que potencialize sua capacidade de ampliar e expandir a informação contida na partitura. 
as mesmas marcas de staccato são usadas para uma serenata ("Ständchen", de Brahms), sarcasmo ("Für fünfzehn Pfennige", de Strauss), desejo ("Ganymed", de Schubert), raiva ("Warte, warte", de Schumann) [... ]. As mesmas marcas de portamento para o piano são vistas para o primeiro amor ("Seit ich ithn gesehen", de Schumann), lágrimas ("Wonne der Wehmuth", de Beethoven), e insônia ("Morgens steh" ich auf", de Schumann). A mesma dinâmica é requerida para descrever um passeio noturno de uma rainha das fadas ("Neve Liebe", de Mendelssohn) e um grupo de almas torturadas no Inferno ("Gruppe aus den Tartarus", de Schubert). (KATZ, 2009, p. 61)

As aptidões e competências requisitadas ao pianista colaborador assemelham-se às que Dalcroze assinalava como ausentes ou insuficientes aos músicos de formação convencional e que impulsionaram suas pesquisas como pedagogo. Na concepção do autor, o músico completo deveria ser capaz de interpretar sutilezas, nuances expressivas imponderáveis, não só de uma sonoridade, como de um silêncio, que, mesmo desprovido de movimento, é repleto de vibração (DALCROZE, 1948, p. 24), bem como saber dosar e orquestrar essas nuances.

Para isso, uma de suas conclusões foi sobre a importância do desenvolvimento da capacidade de improvisação, além do desenvolvimento rítmico geral através da música associada ao movimento, desde o início do aprendizado musical. Assim, torna-se possível despertar no estudante, desde cedo, o desejo de criação, de expressão individual, de dar forma aos sentimentos através da música, permitindo que ele seja o condutor de seu interesse pelos estudos tradicionais, de seus esforços técnicos, do desenvolvimento de seu sentido tátil, de sua audição e de sua musculatura. $\bigcirc$ papel do bom educador, segundo Dalcrozer é criar no aprendiz de música "a simultaneidade de atos inconscientes e atos conscientes, provocar e facilitar seus intercâmbios, estabelecer ligações rápidas entre as faculdades da vontade e de reação, de imaginação, de análise, de realização e criação" (DALCROZE, 1945, p. 191). A seu ver, a prática da improvisação, nas aulas de piano ou de Rítmica, deveria ser um recurso indispensável para desenvolver a percepção dos mais diversos matizes rítmicos, dinâmicos e agógicos da música, a atenção, o espírito de adaptação e a variabilidade. 


\section{Conclusão}

A Rítmica de Émile Jaques-Dalcroze foi criada, a princípio, com o propósito de suprir insuficiências, observadas pelo autor, na formação convencional de Conservatório do músico profissional, no início do século XX, bem como superar entraves, de ordem muscular e nervosa, à prática e interpretação musical, decorrentes, a seu ver, da própria rigidez do sistema pedagógico tradicional vigente, e da reduzida experiência motora-tátil e sensorial, de modo geral, do contexto urbano moderno. Na atualidade, no entanto, ainda é possivel reconhecer semelhantes dificuldades na execução musical, denominadas por ele como "arritmias musicais".

Na função de pianista colaborador, torna-se preponderante, mais do que o preciosismo técnico-instrumental ou a capacidade intelectual de análise musical, a possibilidade de conjugar múltiplas aptidões e competências, abarcando inclusive o domínio textual/literário. Em síntese, segundo Katz, as quatro responsabilidades primordiais da função de colaborador seriam: guardar e manter os desejos do compositor; os requisitos do poeta, conforme a visão do compositor; as necessidades emocionais e físicas do parceiro; e, finalmente, as necessidades expressivas do próprio pianista. De acordo com isso, faz-se essencial ao pianista colaborador, além da capacidade própria a todo bom intérprete de traduzir e explorar as potencialidades sonoras latentes nas indicações da partitura, sob o prisma da sua personalidade artística, colaborar por uma performance com um parceiro, o que exige não apenas uma percepção acurada simultânea de si e do outro, mas também a capacidade de reação e de adaptação rápida a circunstâncias inopinadas e ao que o outro pode oferecer de significativo no momento vivo da performance.

Entende-se que a Ritmica de Dalcroze pode contribuir muito para a formação do pianista colaborador, como prática e como filosofia pedagógica musical, à medida que visa a liberar o instrumentista de condicionamentos adquiridos por repetição, automatismos e gestos inúteis da intervenção constante do pensamento, para torná-lo mais flexível, fluente e capaz de decisões rápidas, sensiveis e criativas, contemplando uma gama vasta de matizes interpretativos. Dalcroze assinala também a importância da relação entre a voz e a audição, da respiração e do gesto musical, implícito no som, para a performance musical, inclusive do 
instrumentista - mostrando-se de especial relevância, para o pianista na função de colaborador ou para prática camerística, de modo mais amplo. Isso resultaria, ao contrário de uma especialização, em uma educação musical geral e essencial a todo músico, dando primazia à vivência sensorial, auditiva e tátil, à experiência espacial e corporal, do gesto e do movimento, através da música, integrando o físico e o psicológico, permitindo que as dimensões humanas do consciente, inconsciente e subconsciente afluam e nutram-se mutuamente, enriquecendo a obra artística.

\section{Referências}

BACHMAN, Marie-Laure. Dalcroze today: an education through and into music. Oxford: Claredon Press, 1993.

BALLESTERO, Luiz Ricardo Basso. "As relações entre texto e música na performance da música vocal, a partir de publicações de pianistas colaboradores". In: CONCRESSO DA ASSOCIAÇÃO NACIONAL DE PESQUISA E PÓS-CRADUAÇÃO EM MÚSICA, 24., 2014, São Paulo. Anais... São Paulo: ANPPOM, 2014.

BERCHTOLD, Alfred. Émile Jaques-Dalcroze et son temps. Lausanne: Editions L'Âge d'Homme, 2005.

DALCROZE, Émile Jaques. Le rythme, la musique et l'éducation. Lausanne: Foetisch Frères, 1921.

La musique et nous: notes sur notre double vie. Genève: PerretCentil, 1945.

Notes Bariolées. Genebra: Édition J.-H. Jeheber, 1948. La rythmique. Lausanne: Jobin \& Cie Éditeurs, 1916, 2 v.

CARDNER, Howard. Estruturas da Mente: a Teoria das Inteligências Múltiplas. Tradução: Sandra Costa. Porto Alegre: Artes Médicas Sul, 1994. 
KATZ, Martin. The Complete Collaborator: the pianist as partner. New York: Oxford University Press, 2009.

LIMA, Sonia Albano (Org.). Performance \& interpretação musical: uma prática interdisciplinar. São Paulo: Musa, 2006.

NICOLETTI, Daniela Amaral Rodrigues. A educação estética através da música no segundo setênio: aproximações entre Rudolf Steiner e Émile Jaques-Dalcroze. 2017. Dissertação (Mestrado). Universidade de São Paulo, São Paulo, 2017.

VASCONCELOS, António Ângelo. O conservatório de música: professores,organizaçãoepolíticas.Lisboa:Instituto delnovaçãoEducacional, 2002. Disponivel em: <http://issuu-download.tiny-tools.com/print.php?doc_ $i d=\mid 40215171512$-fecb2c239 | b02a4a55c0923a l 861332d>. Acesso em: 12 out. 2018.

\section{Sobre as autoras}

Daniela Amaral Rodrigues Nicoletti é Doutoranda em Música pela Escola de Comunicações e Artes da Universidade de São Paulo (ECA-USP) e mestre pela mesma instituição. É bacharel em Composição e Regência, pelo Instituto de Artes da UNESP, e formada em Canto, pela Fundação das Artes de São Caetano do Sul. Sua carreira de musicista desdobra-se em três focos: canto, regência e educação musical. Atua, como educadora musical, no Ensino Formal e Informal, com crianças, desde 2004. Foi ministrante de oficinas de Canto-Coral pela Secretaria Municipal de Cultura de São Bernardo do Campo e pelo Sesc, preparadora vocal do Coro Municipal do Guarujá, coordenadora e artista-educadora do Programa de Iniciação Artística (PIÁ) da Secretaria Municipal de Cultura de São Paulo. Foi fundadora do Coral Patois, da Aliança Francesa, em 2010 , tendo sido responsável por sua direção e preparação vocal até 2014, e do Núcleo Tessituras. Dedica-se à Música de Câmara, em diversas formações. 
Silvia Maria Pires Cabrera Berg, natural de São Paulo, é bacharel em Música com Habilitação em Composição pela Escola de Comunicações e Artes da Universidade São Paulo (ECA-USP). Como bolsista do CNPa, realizou seus estudos de pós-graduação na Universidade de Oslo, onde fixou residência por 24 anos. Fundadora e regente do Ensemble Øresund de 1999 a 2000. Regente titular até janeiro de 2008, do tradicional Københavns Kammerkor e do Grupo AmaCantus. Realizou mais de duzentos concertos na Europa antes de seu retorno ao Brasil em 2008. Como compositora, têm tido suas obras executadas regularmente em concertos e festivais na Europa, América Latina e Estados Unidos, destacando-se sua participação no ISCM World Music Days, de Zagreb, em 2005, com ?Dobles del Páramo? para piano solo. Desde maio de 2008 é docente do Departamento de Música da ECARP (atualmente Departamento de Música da FFCLRP), na área de Educação Musical, atuando ainda nas áreas de Percepção Musical e Regência e Canto Coral.

Recebido em 12/8/2018

Aprovado em 17/10/2018 